Session 3554

\title{
The Educators Corner: A Response to Needs in Entrepreneurship Education
}

\author{
Katherine A. Emery, John Feland \\ Stanford Technology Ventures Program/Center for Design Research \\ Stanford University
}

\section{INTRODUCTION}

Many colleges and universities worldwide have seen the value of integrating entrepreneurship education into engineering and science programs. Creating a new program can provide the opportunity to affect regional economic growth, enhance skill development of the next generation of technology leaders and managers, and create a stronger connection between the university and industry. However, creating a new program presents many challenges as well.

In order to determine the challenges that educators face in developing entrepreneurship programs for engineering students, the Stanford Technology Ventures Program (STVP) distributed a survey to entrepreneurship educators throughout the United States. Responses indicate that the resources required to build a quality program extend beyond textbooks, and include administrative, pedagogical and networking resources.

To assist educators in overcoming these challenges, STVP has developed the Educators Corner, an online instructional resource for entrepreneurship educators. The Educators Corner can be reached via the following URL: http://stvp.stanford.edu/out/educators.html. STVP's interest is to leverage the strengths of all instructional agents - to encourage professors to focus on delivering high-quality entrepreneurship instruction, to leverage regional industry mentors and resources, as well as to use technology's inherent strength as a dissemination tools and communication conduit to support worldwide collaboration. In this paper, we will discuss the results of the survey, online entrepreneurship resources available for dissemination and discourse, and the vision for the future direction of Educators Corner.

\section{THE STANFORD TECHNOLOGY VENTURES PROGRAM}

\section{Overview}

The Stanford Technology Ventures Program (STVP) is the entrepreneurship education center within the School of Engineering at Stanford University. The School of Engineering is home to approximately 3,000 students-more than 25\% of all the degrees at Stanford. Stanford's Wellspring of Innovation, an online database of ventures started by Stanford alumni, indicates that over 50\% of all Stanford affiliated start-ups come from School of Engineering alumni. This creates a huge need and demand for high-technology entrepreneurship education. The STVP 
Program was established in 1995, with the goal to accelerate high-technology entrepreneurship education and research across engineering and science universities worldwide. The program focuses its efforts in three areas:

1) Teaching: to create and deliver curricula for engineering education

2) Research: to support research on high-technology entrepreneurship

3) Outreach: to share results and materials in order to accelerate similar efforts worldwide

Currently, the program provides 20 quarters per year of entrepreneurship instruction, supports 12 PhD students researching high-technology ventures, and hosts an annual conference for entrepreneurship educators. STVP also conducts an internship program, a cross-campus entrepreneurship collaborative network, and a speaker series which brings approximately 25 entrepreneurial thought leaders (CEO's, Venture Capitalists, authors) to speak on campus each year.

\section{Educational vision}

Classes within the STVP program focus on case-based instruction and experiential learning. Entrepreneurship education takes place in the classroom and the community. Students collaborate in teams to research and analyze cases, write business plans, and conduct real-world research and internships within new ventures in Silicon Valley.

John Dewey established the link between doing and knowing. According to Dewey, shared experience or joint action is crucial to the learning process. Educative experiences must lead from the classroom into the real world. The role of the educator is to view teaching and learning as a continuous process of reconstruction of experience. [2] It is through experiential learning that the lessons of entrepreneurship take root. The educators within STVP believe that engineers and scientists need entrepreneurial skills to perform optimally at all levels of an organization, be it in start-ups or established corporations. The goal is to prepare Stanford students to solve problems, to develop ideas and products, to take leadership positions in start-up ventures, in established firms and society as a whole.

\section{Distributed learning}

In January 2001, STVP received a grant from the Kauffman Center for Entrepreneurial Leadership to support its distributed learning efforts and entrepreneurship education outreach initiative. This initiative targets faculty who teach entrepreneurship to engineers and scientists. Over the next three years, STVP will develop instructional resources related to high-technology entrepreneurship education, and offer them online through the Educators Corner.

STVP's interest is to leverage the strengths of all instructional agents - to support educators to focus on delivering high quality entrepreneurship instruction, to leverage regional industry mentors and resources, as well as to use technology's inherent strength as a dissemination tool and communication conduit to support worldwide collaboration. 


\section{SURVEY}

Survey design

In order to determine the needs of entrepreneurship educators - specifically the needs of those who teach in engineering and science environments - the Stanford Technology Ventures Program created and distributed a survey to faculty around the United States. The survey of entrepreneurship educators was conducted early in 2001. Approximately 200 surveys were distributed via email, with a response rate of about $20 \%$.

Questions were organized in the following areas:

Background: teaching background, type of university, challenges currently faced by educators.

Content: instructional resources currently used, what topics are of interest to faculty, how faculty might use new content.

Teaching tools: instructional methods currently used, what online features are of greatest interest to faculty.

Results

One of the major findings of this survey is the domain of challenges faced by educators. These challenges can be organized into two categories: teaching and administrative. Results from the needs survey indicate that entrepreneurship educators are focusing on experiential learning, they want to provide real-world experiences for their students, and are looking for quality materials that can be customized to fit classroom and community contexts, rather than entirely predefined courses. Teaching challenges include issues of content development, content delivery, and distributed education (or distance learning).

Administrative challenges deal with the lack of institutional and/or community support for developing entrepreneurship education programs and the lack of resources available (including time) to assist in program development and management.

\section{a. Teaching background}

We found that over half ( $52 \%$ ) of the survey population taught students within the business school environment. The remainder of the respondents (48\%) taught classes within the school of engineering or school of science. Within the business schools, professors were often working from an established entrepreneurship curriculum and were interested in expanding the student population to include engineers and scientists. In most cases where programs were created elsewhere, there was not a business school previously established, or the business school would not support such an educational initiative. The professors within these programs were working to design an entrepreneurship curriculum that would best meet the needs of their students.

Regardless of the origin of the program, the challenges faced by entrepreneurship educators were similar. 
b. Challenges currently faced by entrepreneurship educators

\begin{tabular}{|l|l|}
\hline $48 \%$ & Shortage of quality teaching materials \\
\hline $40 \%$ & Challenge to provide students with real-world experiences \\
\hline $40 \%$ & Reported that student demand for seats in course exceeds supply \\
\hline $38 \%$ & Lack of support from university, school, administration and/or colleagues \\
\hline $31 \%$ & Shortage of funds \\
\hline $25 \%$ & $\begin{array}{l}\text { Other: no time, lack of instructors with real-world experience AND teaching } \\
\text { credentials }\end{array}$ \\
\hline
\end{tabular}

Educators are faced with teaching and administrative challenges. $48 \%$ were challenged by a shortage of quality teaching materials. Educators requested materials such as case studies (with particular emphasis on high-technology, biotechnology or life science), examples of course outlines, and recommended readings. Individual comments indicated that faculty are not aware of what resources are available to them, or the existing materials are not suitable for individual needs, and there is little time to review the materials. In addition, educators are challenged to provide students with real-world experiences $(40 \%)$. Comments indicated that real-world experiences include faculty experience with new ventures, access to industry leaders, and availability of mentors and internships for students. Administrative challenges focused on lack of support - both financial and human capital. $40 \%$ of respondents indicated that the demand for courses exceeded the availability, and $38 \%$ reported lack of support from the university, school, administration and/or colleagues. 31\% indicate lack of funding, and 25\% cited other challenges, including lack of time, and lack of qualified instructors who have real-world experience and teaching credentials.

\section{c. Instructional resources currently used in the classroom}

\begin{tabular}{|l|l|}
\hline $78 \%$ & Industry speakers \\
\hline $78 \%$ & Case studies \\
\hline $60 \%$ & Textbooks \\
\hline $55 \%$ & Journal articles \\
\hline $45 \%$ & Websites \\
\hline $43 \%$ & Newspapers \\
\hline $33 \%$ & Videotapes \\
\hline $10 \%$ & Computer-based simulations \\
\hline
\end{tabular}

One of the challenges in entrepreneurship education is developing entrepreneurial know-how in the students. Students can study accounting, program management, finance, and other topics focusing on the know-what of entrepreneurship. Without the contextual learning of know-how, students are limited in how effectively they can apply the lessons of these programs. Therefore it is little surprise that the two most-used instructional resources used in entrepreneurship education are industry speakers and case studies. These two methods are acknowledged as very effective contextual learning techniques, as well as dynamic and active classroom methods. The 
remaining resources used by educators are typical of the college classroom environment. These resources are often less customizable to the classroom environment and to the context of the entrepreneurship program. It is also possible that these results reflect a lack of awareness of pertinent resources to assist with courses.

\section{d. How educators want to use new resources}

\begin{tabular}{|l|l|}
\hline $65 \%$ & Customizable material \\
\hline $58 \%$ & Enhance an existing course w/supplemental material \\
\hline $35 \%$ & Pre-requisite \\
\hline $33 \%$ & Entirely new course, asynchronous \\
\hline $20 \%$ & Entirely new course, synchronous \\
\hline $20 \%$ & Enhance entire program offerings \\
\hline
\end{tabular}

It is interesting to note that the need for customizable material is at the top of the list for how educators want to use new resources. $65 \%$ of respondents requested customizable material, and $58 \%$ would like to enhance an existing course with supplemental material. This statistic is not surprising - educators want to design a learning experience to fit within the context of their educational and local communities. For example, an entire course designed at Stanford with resources focused on Silicon Valley might find little applicability at Arkansas Tech University in Russelville, Arkansas (one author's former hometown). However, certain curricular elements used to develop the Stanford course could be combined with elements from other courses to create a new course, targeted at students in Russelville. According to respondents, "blocks" of curriculum, or learning objects [4], are more useful than predefined courses. There is also a need for material to help bootstrap student understanding of prerequisite material such as accounting.

\section{EXISTING ONLINE RESOURCES}

There is a wealth of online resources available for entrepreneurship education, engineering education, and teaching practices. The purveyors of these resources are publishers such as HBSP: Harvard Business School Publishing [5] or McGraw-Hill [6]; foundations such as the Kauffman Center for Entrepreneurial Leadership (Entreworld) [7]; professional societies such as NCIIA: the National Collegiate Inventors and Innovators Alliance [8] and ASEE: the American Society for Engineering Education [9]; governmental organizations such as NEEDS: National Engineering Education Delivery System [10]; or universities such as Babson College's SEE(R) educator training program [11]. Each of these organizations caters to a specific population. There is some overlap in the domains, but no single resource addresses all of these domains. For example, ASEE attempts to bring together the best of engineering educational methods in their website. HBSP overlaps with entrepreneurship education and educational best practices by offering content on entrepreneurship, and instructional guidelines for teaching via the case method. The STVP Educators' Corner will fill this gap in the resources available for educators. The following diagram illustrates the three domains, and indicates where the Educators' Corner will address all three domains: entrepreneurship education, engineering education and educational best practices. 


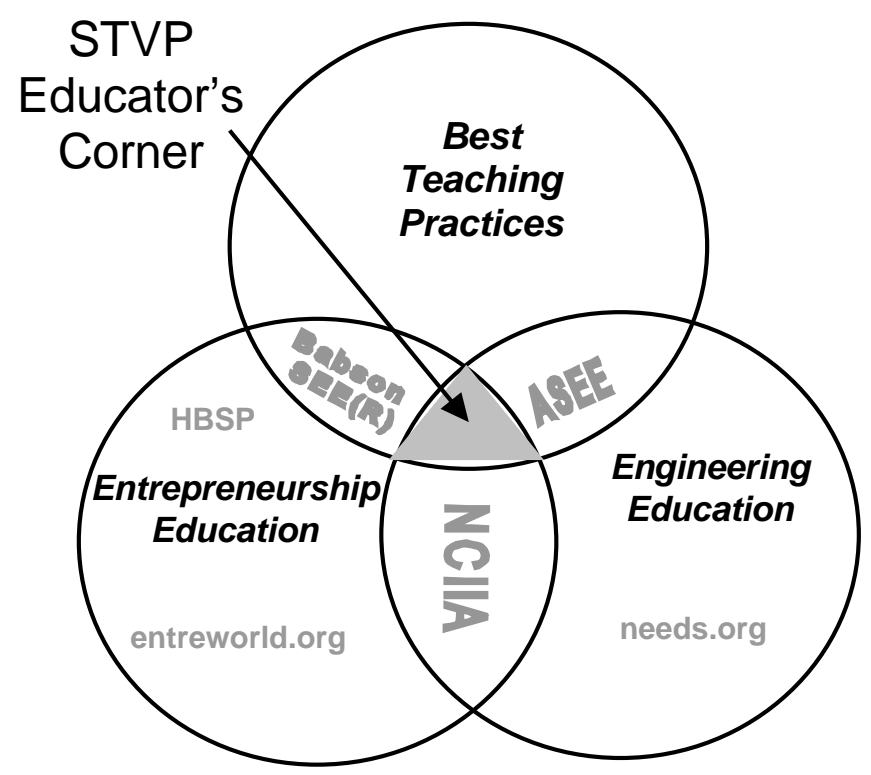

Figure 1: The diagram illustrates the three domains of resources available for educators. There is no single online resource that brings together entrepreneurship education, engineering education and teaching practices. The STVP Educators' Corner will address all these domains by making available the best elements of entrepreneurship education for engineers and scientists.

The above review of existing online resources for entrepreneurship was by no means exhaustive. It was meant to communicate the state of the resources available and illuminate a glaring lack of tailored curricular resources. There is a need for a highly selective online resource for entrepreneurship educators who instruct engineering and science students.

\section{EDUCATORS' CORNER: http://stvp.stanford.edu/out/educators.html}

To address the teaching and administrative challenges faced by entrepreneurship educators, STVP has worked to capture various educational resources used within its own entrepreneurship program and curriculum, as well as those developed in other programs around the country. The Educators' Corner is an effort to glean best practices and resources from world-class entrepreneurship educators and make these resources available in an easy to use, compelling online environment. [1]

Results from the needs survey indicate that entrepreneurship educators are focusing on experiential learning. They want to provide real-world experiences for their students, and are looking for quality materials that can be customized to fit classroom and community contexts, rather than entirely predefined courses. Administrative challenges concerned the lack of institutional and/or community support for developing entrepreneurship education programs and the lack of resources available (including time) to assist in program development and management. 
The resources provide via the Educators' Corner are divided into four focus areas:
a) How to Build a Center
b) Curriculum
c) Tools and Methods
d) Community

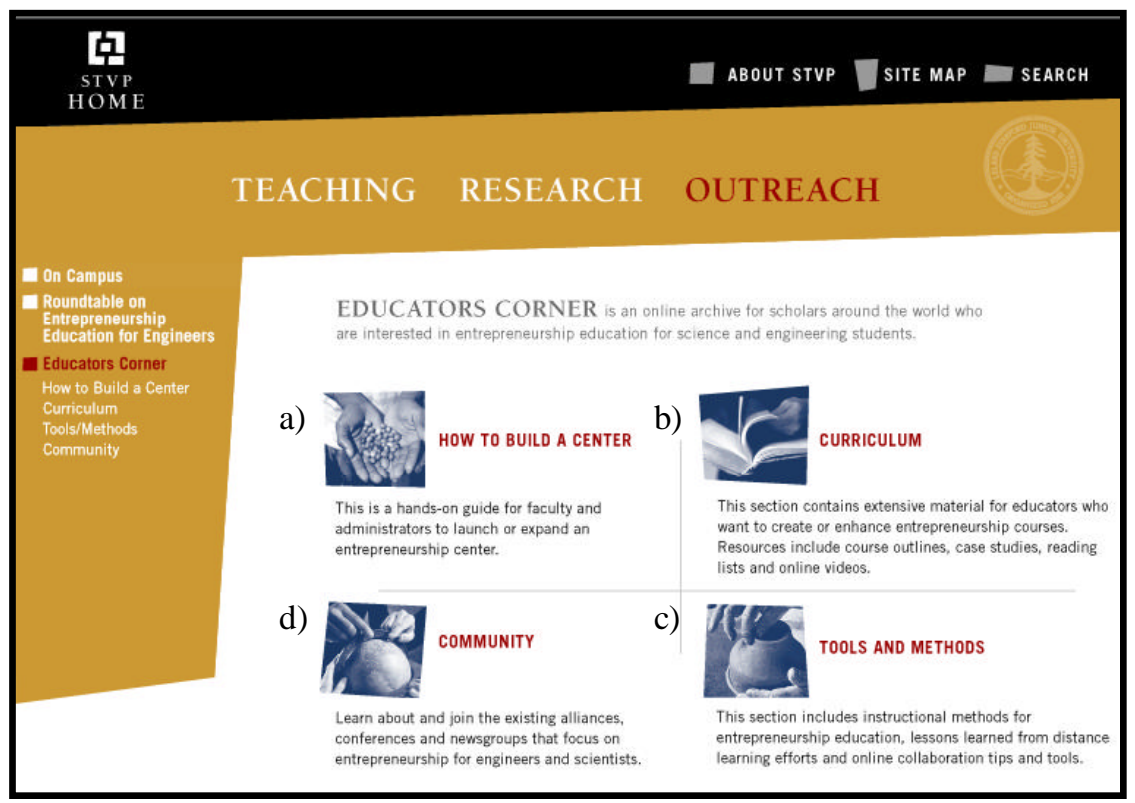

Figure 2: STVP Educators' Corner http://stvp.stanford.edu/out/educators.html

\section{a. How to Build a Center}

This section contains a hands-on guide for faculty and administrators to launch or expand an entrepreneurship center for engineers and scientists. The STVP Overview provides a comprehensive look at the existing program, its history and developments to date. The E-ship Program Overviews highlight 12 programs for engineers and scientists, and include information regarding history, design, mission, student demographics, and program accomplishments. How to Build a Center includes information about why an entrepreneurship program is valuable, identifies key questions that should be asked in order to determine whether or not to build a center, provides ideas for basic and advanced program design, suggests frequent obstacles and solutions, and provides a list of entrepreneurship organizations and resources that may provide assistance. The Faculty Interviews, both written and in digital video format, provide insight into the design challenges educators have considered when developing new entrepreneurship programs.

\section{b. Curriculum for entrepreneurship courses}

This section contains material for educators who want to create or enhance entrepreneurship courses. Because the majority of survey respondents wanted to be able to customize the resources $(65 \%)$, or to enhance an existing course with new materials $(58 \%)$, the curricular materials have been developed as independent learning objects. Current resources include case 
studies and online videos of entrepreneurial leaders. Resources in development include prerequisite courses for topics such as accounting, and simulations of particular concepts such as cash flow. A list of business plan competitions has been compiled, to assist educators in identifying real-world collaborative projects. To aid in the instructional design process, additional resources have been compiled and include reading lists and course outlines.

\section{c. Tools and Methods}

This section includes instructional methods for entrepreneurship education, lessons learned from distance learning efforts and online collaboration tips and tools. Leading entrepreneurship educators around the world are developing hands-on guides for the following:

- Best instructional methods for teaching entrepreneurship to engineers

- Using video in the classroom

- Teaching via the case method

- Designing for experiential learning

In addition, journal articles will be highlighted to support educators with how, and why, to use various technologies to design unique learning experiences in the entrepreneurship classroom. Such examples include:

- Online collaboration tools

- Creating a classroom community online

- Real-time case writing through teleconferencing

- Cross-university collaboration

- E-mentors: Transcending geographical barriers to provide real-world content

\section{d. The Community}

Individual comments regarding the challenges faced by entrepreneurship educators indicated that many faculty lack the time to review resources, and miss having a peer group with whom to share teaching ideas and practices. This section is designed to promote involvement in existing social networks for engineering entrepreneurship educators, such as organizations, foundations and societies whose efforts are focused on engineering education, entrepreneurship education and the use of technology in education. Resources include conferences, teaching workshops, entrepreneurship foundations, email lists and newsgroups, engineering, entrepreneurship and education societies. Further plans include developing a virtual community of engineeringentrepreneurship educators.

\section{NEXT STEPS}

Preliminary research shows that the opportunities to provide instructional content to entrepreneurship educators through the Educators' Corner - to influence what and how entrepreneurship is taught - are significant. Creating a distributed learning program, where faculty can obtain and share resources with each other, takes advantage of all instructional agents. Educators are supported to focus on delivering high-quality entrepreneurship education within the classroom and community context, to use technology to transcend geographical 
barriers and provide students with access to industry leaders, and collaborative projects worldwide.

\section{Survey}

We plan to administer new surveys to entrepreneurship faculty to obtain more data. Additional questions will focus on faculty and student demographics, teaching background and instructional practices. Further evaluation of the needs of educators in business, engineering and science programs (undergraduate and graduate) will serve to identify how instructional and administrative needs may differ. The survey will be made available online to capture the interests of those who come to the Educators' Corner in search of resources. In addition, separate surveys will be created to identify student needs. The responses will be compared with faculty responses, and content development modified where applicable.

\section{Educators' Corner}

The Educators' Corner has an initial infrastructure in place to support the four focus areas: How to Build a Center, Curriculum, Tools and Methods, and Community. Further development of content will focus on the development of digital video of entrepreneurial leaders, publication of case studies, creation of instructional guidelines for the Tools and Methods section, and the development of an engineering-entrepreneurship Educators' community through face-to-face and online contexts [3]. As it is in development, the content will be tested by faculty within classroom environments. In addition, we plan to experiment with member and query-based profiling, to allow for personalization of the content.

\section{BIBILIOGRAPHY}

1) Chen, John, et al. "Technology in Engineering Education: What Do the Faculty Know and Want?" Journal of Engineering Education, vol. 89, no. 3, 2000, pp. 279-283.

2) Dewey, John. Experience and Education. Macmillan, New York, NY, 1938.

3) Kim, Amy Jo. Community-Building on the Web. Peachpit Press, Berkeley, CA, 2000.

4) “Standards for Learning Object Meta Data," Institute of Electrical and Electronics Engineers, Inc. (IEEE), 2000. http://ltsc.ieee.org/wg12/s_p.html

5) Harvard Business School Publishing: http://www.hbsp.harvard.edu/educators

6) McGraw-Hill Education: http://www.mheducation.com/

7) Entreworld: http://www.entreworld.org/

8) National Collegiate Innovators and Inventors Alliance: http://www.nciia.org 
9) American Society of Engineering Education: http://www.asee.org

10) National Engineering Education Delivery System: http://www.needs.org

11) Babson See-Reflect: Symposium for Entrepreneurship Educators:

http://www2.babson.edu/babson/babsoneshipp.nsf/Public/entOrganizationPriceBabsonPrograms

\section{BIOGRAPHICAL INFORMATION}

KATHERINE A. EMERY is the Director of Educational Technologies and manages the TREE project (Teaching Resources for Entrepreneurship Educators) within the Stanford Technology Ventures Program in the School of Engineering. She earned a master's degree in Learning Design and Technology from the School of Education at Stanford, and has published in the areas of cross-disciplinary teamwork, and assessment of online collaboration.

JOHN FELAND is a Research Associate at the Stanford Center for Design Research. A former Assistant Professor of Engineering Mechanics at the United States Air Force Academy, he has returned to Stanford to finish his PhD in Mechanical Engineering. He has published in the areas of design education, systems engineering requirement creation and management, risk management systems, innovation, entrepreneurship education, and team building. 